\title{
Information and Technology (ICT) usage in Al-Ula Schools (An Application of Tearle's Framework)
}

\author{
Dr. Fahad Albalawi \\ General Directorate of Education in Madinah - Saudi Arabia \\ Email: Foa1441@gmail.com
}

\begin{abstract}
This paper discusses the findings from a recent study into the current status of and challenges to information and communications technology (ICT) usage in Al-Ula schools, as viewed from the perspective of teachers and principals within the schools. In this study, several themes that highlighted the status of and challenges to ICT use. Findings from the study showed that while Al-Ula schools were equipped with technology that was inadequate to serve the needs of teachers in the schools. Additionally, this technology was often difficult to maintain and repair due to a lack of technical support, and funding from the Ministry of Education was insufficient to equip the schools properly. Most teachers and principals likely needed more training in ICT use. There appeared to be an overall positive attitude toward technology use, yet the schools lacked a strategic plan for ICT implementation. These findings are discussed within the context of Tearle's (2004) A Theoretical and Instrumental Framework for Implementing Change in ICT in Education, which suggests that ICT implementation is most effective when it takes the organization, the individual, practical and material artefacts, and the change process into account.
\end{abstract}

Keywords: Information and communication technology (ICT), change implementation processes, education in Saudi Arabia, instructional uses of ICT, AlUla school district. 


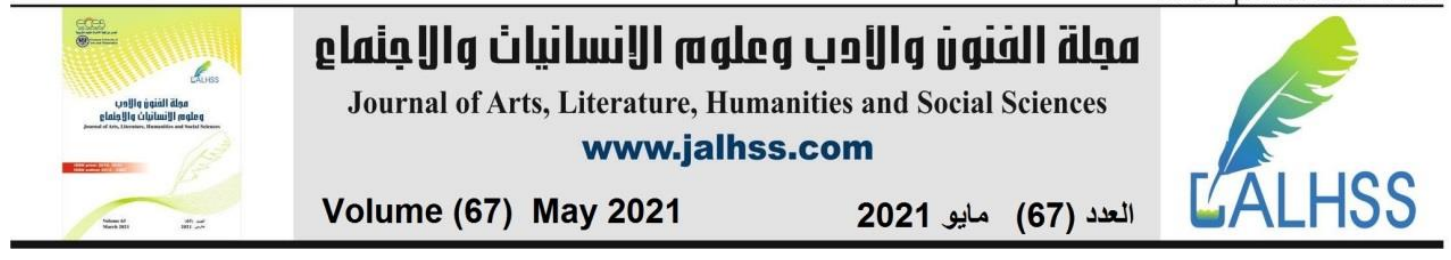

Introduction

The purpose of this study was to discover both the current status of and challenges to information and communications technology (ICT) usage in Al-Ula schools, as viewed from the perspective of teachers and principals within the schools. Through analysis, which included coding interview and survey data, looking for patterns, and comparing the data to findings in previous literature, several themes emergedthat highlighted the status of and challenges to ICT use. Specifically, data from this study showed that while Al-Ula schools were, as noted in the previous chapter,equipped with a variety of ICT hardware and software, this technology was often obsolete, not functioning properly, and/or inadequate to serve the needs of teachers in the schools. Additionally, this technology was often difficult to maintain and repair due to a lack of technical support on school grounds, and funding from the Ministry of Education was insufficient to equip the schools properly. Most teachers and principals appeared to have some basic ICT training, but more training is likely needed, especially as new technologies an require ongoing learning, and teachers did not appear to be knowledgeable about interactive teaching methods using technology. In terms of the attitudes of teachers and staff, while most were dissatisfied with the current state of ICT in their schools, there appeared to be an overall positive attitude toward technology use. Principals appeared to promote a supportive and encouraging atmosphere, yet lacked a strategic plan for ICT implementation. This was echoed at the Ministry of Education level, where ICT implementation appeared to be a national objective, but more active direction and support for technology use was lacking.

\section{Questions:}

1. In what ways do teachers use or not use technology in Al-Ula schools?

2. What do teachers and principals identify as the challenges to implementing educational technology in Al-Ula schools?

3. What are teachers' and principals' recommendations to these challenges?

Research methodology: The researcher used the descriptive method in this study.

This chapter will focus on further discussion and analysis of these findings as they pertain to the current literature, with a particular emphasis on comparing my findings to Tearle's (2004) A Theoretical and Instrumental Framework for Implementing Change in ICT in Education, which framed for this study. According to this theory, ICT change implementation is most effective when it takes the organization, the individual, practical and material artifacts, and the change process into account. An in-depth discussion of these concepts as they pertain to the data from the current study follows.

\section{ICT Implementation - Practical and Material Factors}

According to Tearle (2004), practical and material factors should be considered fundamental elements of the ICT change implementation process. In essence, the organization should have the resources, equipment, and infrastructure needed to implement the desired changes. From Tearle's point of view, there are several 


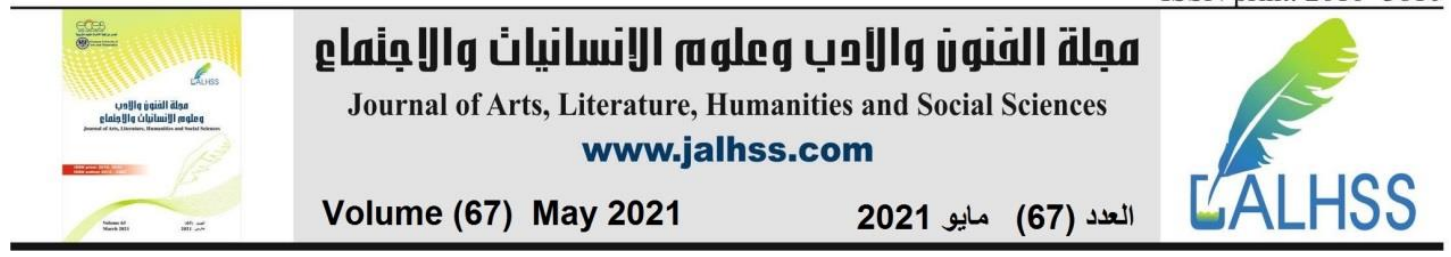

dimensions to be considered as they pertain to the material and practical factors that promote or inhibit ICT implementation, as shown in Table 5.1.

\section{Table 5.1}

Practical and Material Factors for ICT Implementation

\begin{tabular}{|c|c|}
\hline Dimensions & Questions \\
\hline $\begin{array}{l}\text { Resources (e.g. Hardware } \\
\text { Software, etc.) }\end{array}$ & $\begin{array}{l}* \text { Are there sufficient computers and are they fit for } \\
\text { purpose? } \\
* \text { Where are they located and how is access arranged? } \\
* \text { Are they reliable? }\end{array}$ \\
\hline Training and Support & $\begin{array}{l}\text { * Is there a program relating to development of ICT } \\
\text { use? } \\
* \text { Does it address pedagogical need as well as skills? }\end{array}$ \\
\hline Technical Support & $\begin{array}{l}\text { * Are technical, senior manager and peer support } \\
\text { structures are in place? }\end{array}$ \\
\hline Coordination and Management & $\begin{array}{l}* \text { How is ICT coordinated? } \\
* \text { Who are the key people and what are the processes? }\end{array}$ \\
\hline
\end{tabular}

The findings from the current study offer some answers to Tearle's questions as they pertain to the practical and material factors influencing ICT implementation in Al-Ula schools. In particular, this study showed that while there were computers available, the ways in which they could be used was limited. Computers were often available in every class and in science labs, but generally only the teacher had access to them. Participants noted that the internet access was slow enough to impede proper computer function. Findings also showed that there was no technical support staff on hand or meaningful structure in place to repair technology when it was needed, to update computers in a timely manner, or to perform other routine maintenance. Technical support from off campus often took weeks to fill repair requests, if they could fill them at all. The workaround solution devised by some schools was to have technically-savvy teachers and principals stand-in as technical support, fixing/maintaining whatever they could within the limits of their capabilities. In terms of coordination and management, the process appeared to be ad-hoc. Accessing, using, and maintaining computers did not appear to be carefully coordinated in any way that was detected by this study.

Findings from this study demonstrated that the primary uses of ICT among teachers were teacher-centered. If the purpose of ICT was to aid a teacher in giving a lecture and managing their class, then it can be fairly said that the ICT in Al-Ula schools was fit for purpose. However, a teacher-centered model of ICT usage is both limited and out of alignment with the objectives set forth in the Ministry of Education's Education and Vision 2030plan (2019). This plan was established in response to Saudi Arabia's Vision 2030 (2019), which established a plan for Saudi Arabia to develop a more sustainable economy that was less dependent on oil in the future, including plans for the education and training of young people. In Education and Vision 2030,the Ministry of Education (2019) stated that increasing active learning 


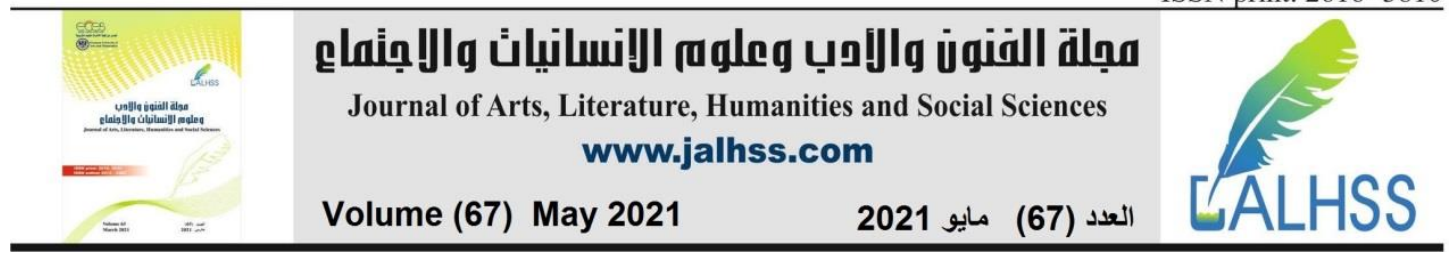

through ICT and developing a more student-centered pedagogy were core objectives. They noted the need for "developing such teaching methods that focus on the learner not on the teacher, and concentrate on inculcating skills, personality development, improving confidence, and promoting spirit of creativeness," along with developing a stimulating school environment that is integrated with ICT systems. In other words, the Ministry established an objective to create a more learner-centered classroom that integrates ICT in order to better prepare students to adapt to changes in the Saudi economy.

In this way, the Ministry is in alignment with Pall and Batra (2016), Pelgrum (2001), and Edwyn (2001), who noted that the true potential of ICT lies in its ability to facilitate active, student-centered learning, critical thinking, and complex problemsolving. Based on their study of ICT implementation in Indian schools (which faced similar challenges to those faced by Al-Ula schools in the current study), Pall and Batra (2016) noted that:

Learning and schooling can be enormously transformed through the use of ICT. ICT gives the freedom to the learners to locate relevant information, judge the credibility of their sources, engage in collaborative problem solving, and take responsibility for how and what they learn. Young learners want to think for themselves and come up with their own complex questions and provides students the space to do this in school time. Multimedia can effectively demonstrate and develop the understanding of the concepts, the syllabi curricula alone is not the only medium to develop learning amongst the students.(p. 84)

According to Pall and Batra, the true value of using ICT as part of a school curriculum is not in how it helps teachers to supplement their traditional ways of teaching, but in completely transforming instruction so that the students are placed at the center of instruction. In this way, students are encouraged to develop their own questions, to take more control over their learning, and to collaborate with their classmates to solve complex problems. These sentiments are echoed by Edwyn (2001), who noted that the "The value of this technology is to open up a vast, unprecedented, and up to now unimaginable, range of activities. These both connect with the child's desires what children love and like to do and with the deepest ideas of science, culture, history, project management and entrepreneurial thinking and whatever" (p. 110). The goal in student-centered instruction is not to replace the traditional curriculum with whatever the student wants, but to use ICT to facilitate the engagement of both individual students and collaborative groups of students with the established content of the curriculum.

While the Ministry of Education and various scholars have pointed to the importance of using ICT facilitate student-centered learning, Al-Ula schools were not using ICT to facilitate student-centered learning at the time of this study. Instead, instructional ICT use was mostly teacher-centered, while interactive ICT use among students was not being practiced widely. That is, teachers used technology to aid them in their work - to prepare lessons and exam questions and to track student progress. In front of the class, teachers used technology to present lessons using PowerPoint and projectors, perhaps using internet applications such as Google or YouTube within 


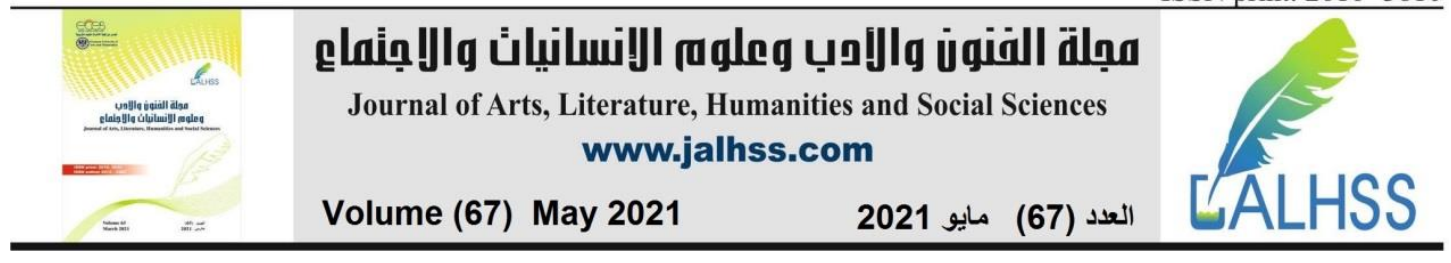

their videos. A more interactive use of computers is essential to create the kind of student-centered learning environment that the Ministry stated as an objective, and that scholars have advocated for. It is worth noting, however, that the teachers who participated in this study had little choice in the matter-the number of computers the students had access to would have prevented more student-centered pedagogies from being implemented, regardless of the wishes of teachers, principals, and students.

An additional barrier to more advanced uses of ICT was a lack of a discernible training program for teachers. Many participants in this study appeared to have some form of training on basic computing skills, whether formally gained through classes or informally gained from sources such as YouTube. Participants often mentioned getting their training while university students, which could mean that the technology they were trained on was obsolete by the time of the study. None of the participants mentioned training on more advanced technology, and none mentioned having been trained on using ICT within a more student-centered pedagogical model. In this way, this study confirms the findings of Al-Asmari and Rabb Khan (2014), who noted how the lack of training in Saudi Arabia contributed to a limited understanding of how to promote e-learning. They stated that "there is need to redefine or amend some principles, policies and tasks associated with the current e-learning environment, in order to re-orient it toward collaborative learning; to provide training and technical support to faculty staff as they revise their teaching materials and methods" (p. 10). With this in mind, the basic training that many of the participants in this study had received was insufficient to truly re-orient the classroom away from teacher-centered instruction and toward student-centered instruction. These findings are similar to those of Abhumaid (2011) who found that teachers changed their instructional strategies as a result of ICT training, with most saying that their instruction had improved in general, and most reporting that ICT training resulted in a more studentcentered classroom environment. The results of these studies show that Al-Ula teachers need not only additional hardware and software, but additional training on how to restructure their curriculum with an emphasis on collaborative learning using ICT.

As it pertained to practical and material factors that are necessary for effective ICT usage in an educational settings, the findings of this study are similar to those of $\mathrm{Al}$ Mofarreh (2016), whose study of Saudi Arabian schools highlighted several barriers to ICT implementation, including inadequate technology and a lack of an organized plan to train teachers on ICT use. Likewise, Pelgrum (2001), in an assessment of ICT use across multiple countries, noted the importance of both professional development/training and in ensuring adequate hardware/software in implementing ICT, especially when the goal is to create more student-centered learning environments. The findings from the current study confirm those of Pelgrum's study, but with a particular emphasis on Saudi Arabia. Additionally, findings from the current study showed that funding for technology from the Ministry of Education did not allow for schools to acquire the additional technology they needed. A robust training program will also require considerable funding from the Ministry, but may be necessary in order to meet the more advanced objectives of ICT use. If these practical 


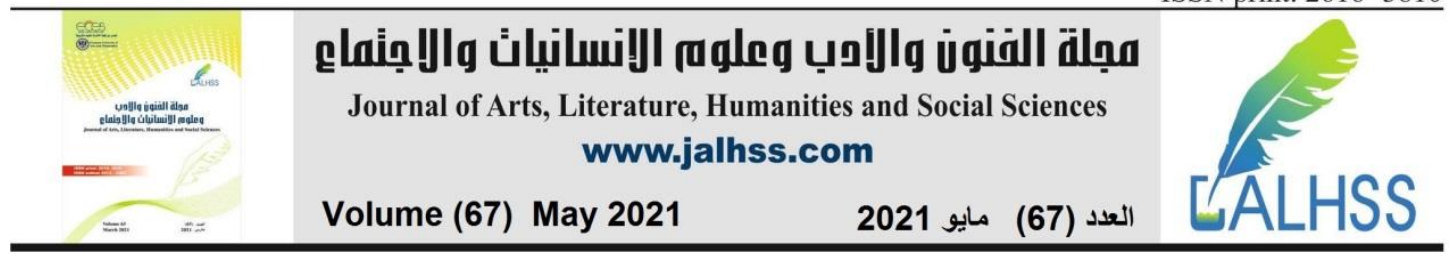

and material factors are not addressed, Al-Ula schools will continue to lack the necessary technology, training, and technical support needed to properly implement and sustain ICT implementation.

\section{ICT Implementation-The Organization}

According to Tearle (2004), the overall culture, practices, and processes of a whole school must be supportive of ICT implementation in order for it to be effective. In particular, Tearle noted that the following features should be present:

- Strong whole school leadership.

- The culture of the school as one which promoted and encouraged learning and could be described as both adaptive and collaborative.

- The change-orientated nature of the whole school and the motivation of individuals within it.

- The positive and proactive attitude to external influences, either mandatory or "opportunities."

- Well-established whole school internal processes.

Findings from this study revealed some aspects of the overall school culture that were likely to be more supportive of ICT implementation, and some aspects that were likely to be less supportive. On the positive side, principals in this study appeared to be encouraging of teachers using ICT within their classrooms, demonstrating and modeling an overall positive attitude toward technology use. The teachers also had a positive attitude toward technology, and appeared motivated to continue using it, despite their dissatisfaction with many aspects of the current ICT infrastructure that was in place (slow internet, inadequate software and hardware, lack of technical support and so on).

At the same time, several of the whole-school qualities that Tearle (2004) indicated would promote ICT implementation were either not present or not discernable by this study. In particular, there did not appear to be a clear strategic plan for ICT implementation, which also pointed toward a lack of strong, proactive leadership that followed an established whole-school process for implementing ICT. This study demonstrated that there was a lack of policy and direction for ICT implementation from the Ministry of Education, despite the fact that the Ministry had explicitly stated ICT implementation as one of its objectives. It is worth acknowledging the important part that the Ministry plays in supporting ICT implementation within schools. It is reasonable to expect the Ministry to define its policy and to provide the school with the necessary resources needed to carry out that policy. In that regard, the current study confirms the position of Al-Asmari and Rabb Khan (2014), who noted that clear policy and direction at the national level would help ensure the success of ICT implementation at the local (i.e. school) level. In its Education and Vision 2030 plan, the Ministry stated its intention to develop a philosophy, policy, and goals of curricula with a means of developing that curricula that would be connected to programs of teacher preparation and professional development. However, evidence from this study indicated that none of those objectives were being experienced by teachers and principals at Al-Ula schools. If those objectives were clearly enacted by the Ministry 


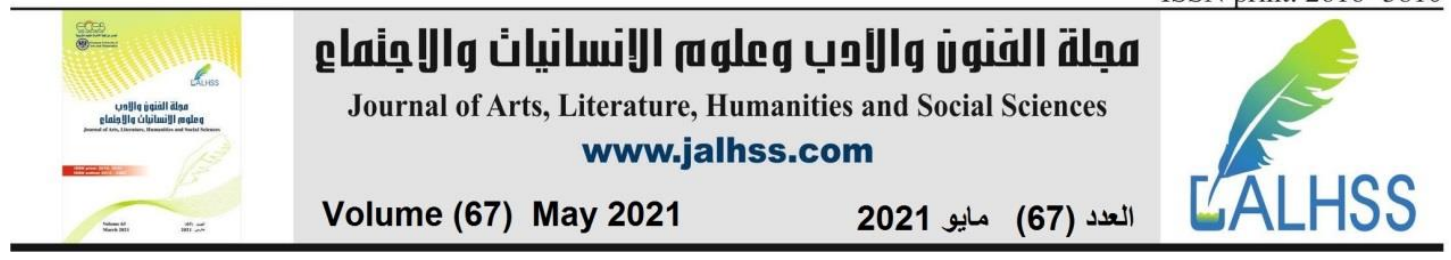

and supported with on-the-ground resources, it is highly likely that this initiative would be beneficial to schools.

In this regard, the findings from this study confirm those of Tondeur et al. (2008), who noted the importance of establishing a clear vision for ICT implementation that was shared from the national level down to the teachers, and that was supported with the necessary resources to make that vision a reality. That is, ICT policy should be focused on creating a shared vision for its use, drawing upon not just objectives of the Ministry, but also on input from teachers and principals. Additionally, the current study supports the findings of Tondeur et al. as it pertains to the role of the school principal in developing a plan to implement ICT policy locally. As Tondeur et al. stated, the principal's capacity "to develop and articulate, in close collaboration with other actors from the school community, a shared vision about ICT use and integration is considered as a critical building block" in the ICT implementation process (p. 221). With that in mind, ICT policy should not only be established by the Ministry, but training and guidance should be given to principals on how to implement that policy at their schools.

While it is evident from the current study that more support and direction from the Ministry is needed, it is also important to consider the current culture inside the schools themselves. As Tearle (2004) noted, change implementation is most effective when the school exhibits a positive and proactive attitude toward external influences. Some evidence from this study demonstrates that the principals were more reactive to external influences, and appeared to be waiting for direction from the Ministry rather than developing their own whole-school processes. Additionally, they noted the "lack of incentives" for technology use from the Ministry, suggesting that the teachers needed those incentives in order to be motivated to use ICT. However, responses from the teachers contradicted that notion, as teachers appeared to have an overall positive attitude toward ICT implementation despite a lack of incentives from the Ministry. Thus, the findings of this study conflict with those of Al-Asmari and Rabb Khan (2014), who found that "organizational support, in the form of incentives, was found crucial to motivating faculty members" to implement ICT (p. 8). The findings from the current study beg the question about what might be accomplished within schools if, rather than waiting for guidance and encouragement from the Ministry, they looked within their own schools and developed their own processes, plans, and incentives. Findings from this study demonstrated that one exceptional school was able to do this, devising plans and incentives for ICT use in lieu of plans and incentives from the Ministry.

\section{ICT Implementation-The Individual}

According to Tearle (2004), one of the essential elements of the change implementation is the attitudes and beliefs of individuals within the organization. In order for ICT implementation to be effective, the people within an organization should have a positive attitude toward teaching and learning using ICT, to recognize its benefit relative to other methods of instruction. According to Tearle, the individual dimension of ICT implementation centers around the following questions:

- What are individual attitudes to using ICT for teaching and learning? 


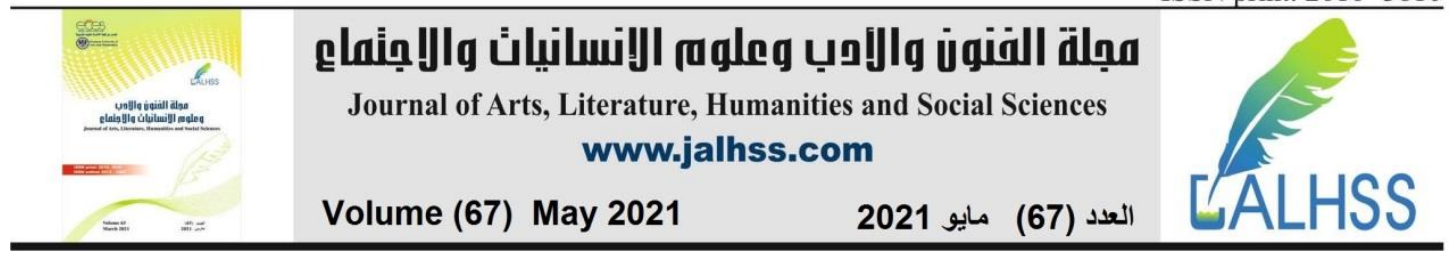

- How motivated and committed are people in general and toward ICT use?

- Do people think they have some degree of control and choice over their actions in relation to ICT use?

- Do people understand how ICT can enhance teaching and learning and see the value in using it?

- To what extent do individuals function as "critical consumers," developing their own personal strategies for implementing ICT?

With regard to the individual dimension, the findings from this study indicate some positive signs for ICT implementation. In general, participants displayed a high degree of motivation and commitment toward ICT use, and appeared to recognize its value in teaching and learning. Participants appeared to recognize that using ICT in teaching was an effective way to engage students, and they recognized how ICT improved the efficiency of their administrative tasks. It is worth noting that participants believed in ICT enough that they sometimes used their own money to purchase or repair equipment, and they spent their time repairing and maintaining equipment when necessary, regardless of whether or not this was part of their job description. In other words, the participants were motivated enough to use technology that they attempted to compensate for what was lacking, including technical support and funding from the Ministry of Education. This motivation also appeared to be intrinsic, driven by a belief in the value of ICT rather than requiring extrinsic motivation in the form of incentives from the Ministry or any other source.

In this way, the teachers in this study exhibited the underlying mindset that has been shown to be conducive to ICT implementation. That is, the participants displayed the kind of goal orientation and recognition of value that would motivate them to use ICT. They were therefore in alignment with the findings of Zhao and Cziko (2001), who noted the importance of teachers being goal-oriented, purposeful agents in order to implement ICT effectively. Zhao and Cziko pointed out three necessary conditions for teachers to use ICT:

1. The teacher must believe that technology can more effectively achieve or maintain a higher-level goal than what has been used.

2. The teacher must believe that using technology will not cause disturbances to other higher-level goals that he or she thinks are more important than the one being maintained.

3. The teacher must believe that he or she has or will have the ability and resources to use technology.

In essence, the teacher must feel like using technology is beneficial to their teaching, helping them to teach more effectively than they would without technology. In both the interviews and surveys in the current study, teachers demonstrated that they saw the value in using ICT, and that it improved the quality of their work. This points to a good foundation for ICT implementation.

To the extent possible, it appeared that the teachers were "critical consumers," developing their own strategies for ICT use. They appeared to have some choice in how they used whatever technology they had available to them to engage students, plan classes, and manage their administrative tasks. 


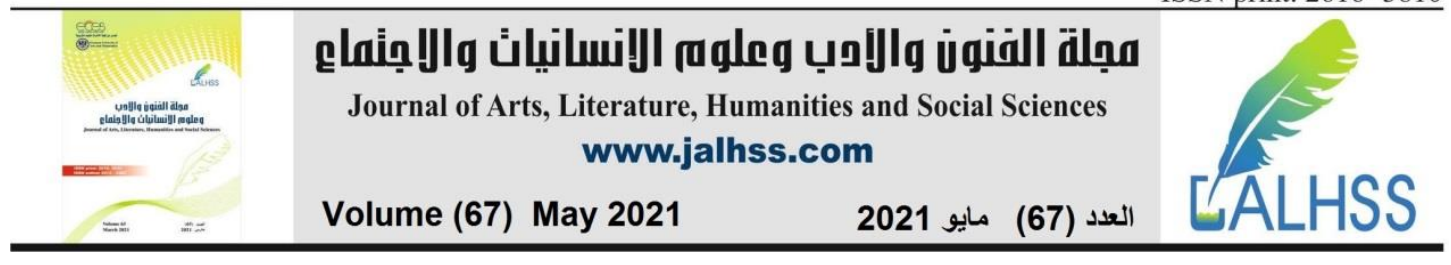

At the same time, Zhao and Cziko's(2001) third criteria was not being met. To the extent that they had training, some teachers may have been confident in their ability to use technology, but as previously mentioned, they did not have the resources they needed to do so effectively. This lack of resources may not only be a practical and/or material concern, but a psychological one as well. One of the essential aspects of being motivated to achieve goals is the belief that they can actually be achieved, that the goal-oriented person has control over whether or not the goals can be achieved. If teachers feel like they do not have the necessary resources to achieve their goals, they may begin to see the pursuit of them as futile. Although they may have had some ability and willingness to choose how they used the technology available to them, their choices were limited by several of the factors listed above: the lack of resources, equipment, training, and technical support needed to have a full range of options at their disposal. This likely explains the disparity between the high level of motivation and the low level of satisfaction experienced by participants. In other words, they were motivated to use technology, but dissatisfied with the level of support, training, and resources they had received in order to use technology effectively.

While the participants appeared undaunted by the lack of resources and support at they had at the time of the study, it is reasonable to question whether or not there could be a tipping point where their dissatisfaction breeds a level of frustration than causes them to give up, to become more resistant to future change out of fear that they would not have the support needed to follow through on any proposed change. The concern here is that teachers and principals could develop a fear of failure based on past experiences of being unable to successfully use ICT that would lead to a resistance to change. Alwani and Soomro (2010) noted many of the same barriers to ICT implementation in their study as were noted in the current study, including a lack of teacher training, and a lack of adequate hardware and software, based on a lack of budget to acquire that technology. This lack of resources can cause repeated failure implement ICT in the manner desired, resulting in a vicious cycle wherebyfear of failure is reinforced by failure to use IT successfully, and the more the teacher internalizes this fear of failure, the less likely they will be willing to use ICT in the future, and the more resistant to change they will become. As Tearle (2004) noted, resistance to change is one of the primary obstacles to ICT implementation.

\section{ICT Change Implementation Process}

In addition to whole school, practical, and individual factors needed for change implementation, Tearle (2004) also examined the factors present in the change implementation process itself. In order to accomplish this, Tearle's study focused on a school that underwent a carefully planned and managed ICT implementation. Through her study, she devised multiple dimensions and questions that are relevant to change implementation. These are as follows:

Table 5.2

ICT Implementation Process

\begin{tabular}{|l|l|}
\hline Dimensions & Questions \\
\hline The Process & $*$ Is the change seen as bringing in something \\
\hline
\end{tabular}




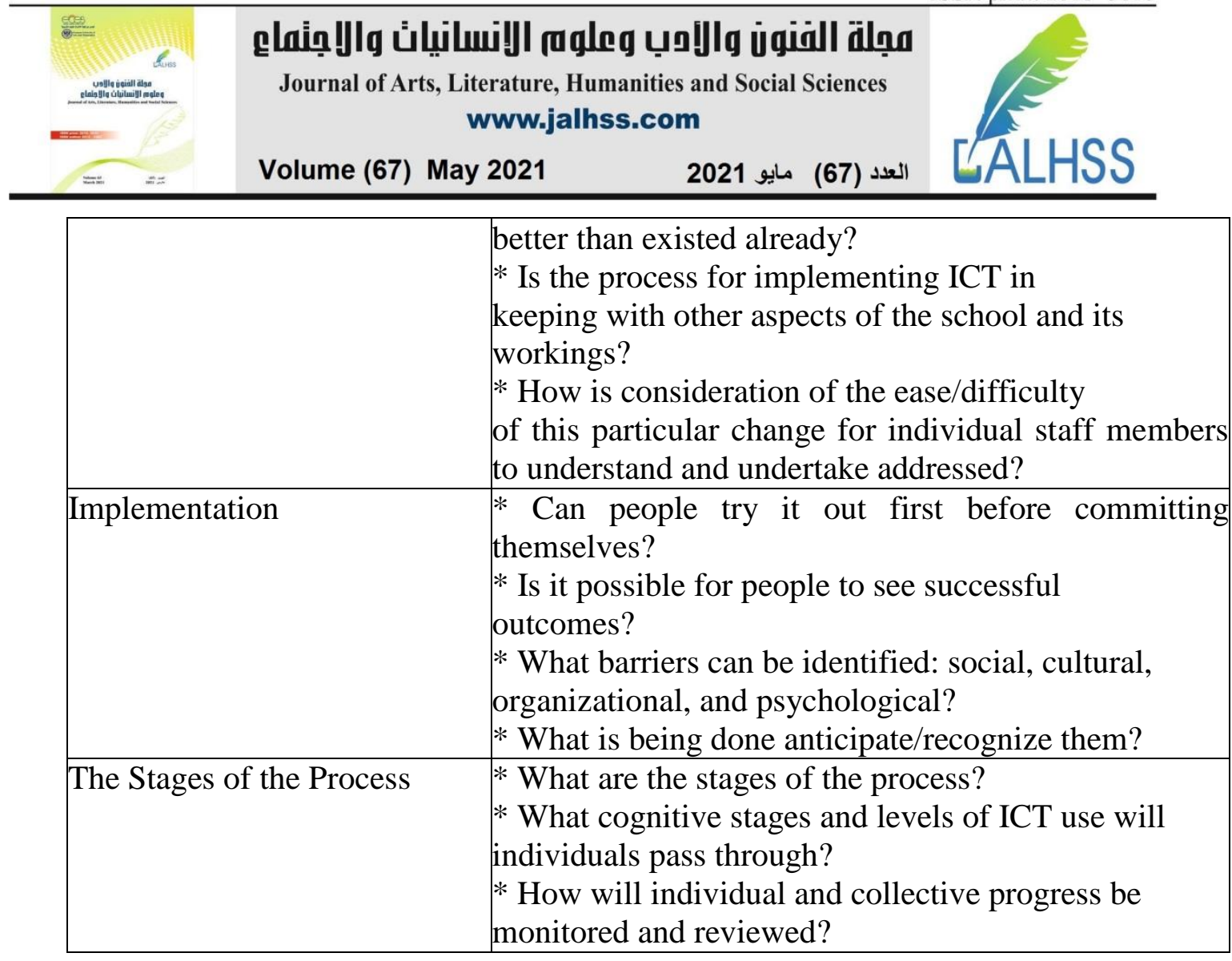

While these questions offer a valuable guide to a well-designed implementation process, most of the questions lie beyond the scope of the current study. If anything, the findings from the current study demonstrate that Al-Ula schools have not undergone a carefully managed and planned ICT implementation process, as evidenced by indications that there was a lack of clear policy or direction at the national level, and a lack of clear plan at the school level. Very likely, the barriers identified in the current study (e.g. inadequate technology, technical support, and training) would need to be addressed prior to or concurrent with a carefully planned ICT change implementation. At the same time, it appeared that teachers and principals were ready for the change to be implemented. Based on their responses to interview questions and surveys, most of the participants would be likely to view further ICT implementation as bringing in something

better than existed already, and that it would be in alignment with their overall objectives for their schools. The next step for Al-Ula schools would be to develop an intentional change implementation process.WithTearle's framework in mind, that process would take into consideration the difficulties that staff would have in implementing the change, and provide the training and practice necessary for staff to overcome those difficulties. This part of the process would involve acknowledging the various barriers that currently exist (including those identified by this study) and anticipating additional barriers that may arise. The change would also be rolled out in stages, with monitoring and assessment along the way to determine whether collective and individual benchmarks are being met. In the event that more training is needed for individuals and/or the collective to pass into the next stage, that training would be 


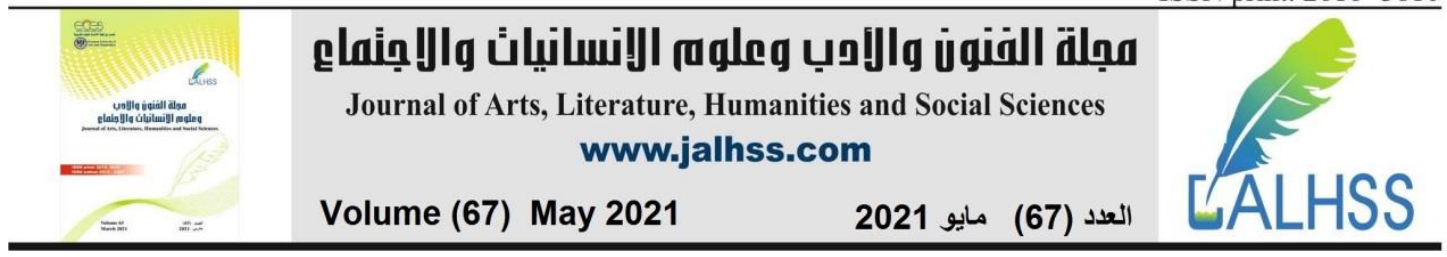

provided. Following this kind of planned, intentional change process would increase the likelihood of success in ICT implementation.

\section{References}

1. Abuhmaid, A. (2011). ICT training courses for teacher professional development in Jordan. Turkish Online Journal of Educational Technology-TOJET, 10(4), 195210.

2. Al-Asmari, A. M., \&Rabb Khan, M. S. (2014). E-learning in Saudi Arabia: Past, present and future. Near and Middle Eastern Journal of Research in Education, 1-11. doi:10.5339/nmejre.2014.2

3. Albirini, A. (2006). Teachers' attitudes toward information and communication technologies: The case of Syrian EFL teachers. Computers \& Education, 47, $373-$ 398. doi:10.1016/j.compedu.2004.10.013

4. Albugami, S. (2016). Developing a strategic approach to ICT implementation in Saudi secondary schools(Unpublished doctoral dissertation). University of Salford, Salford, United Kingdom. Retrieved from http://usir.salford.ac.uk/id/eprint/40206/

5. Al-Hazmi, S. (2003). EFL teacher preparation programs in Saudi Arabia: Trends and challenges. Tesol Quarterly, 37, 341-344. doi:10.2307/3588509

6. Al Mofarreh, Y. I. (2016). Implementation of ICT policy in secondary schools in Saudi Arabia (Unpublished doctoral dissertation). University of Wollongong, Wollongong, Australia. Retrieved from https://ro.uow.edu.au/cgi/viewcontent.cgi?referer $=\&$ httpsredir $=1 \&$ article $=5731 \&$ cont ext=theses

7. Al Mulhim, E. (2014). The barriers to the use of ICT in teaching in Saudi Arabia: A review of literature. Universal Journal of Educational Research, 2, 487-493. doi:10.13189/ ujer.2014.020606

8. Alqarni, A. A. (2015). Educational technology in Saudi Arabia: A historical overview. International Journal of Education, Learning and Development, 3(8), 6269. Retrieved from http://www.eajournals.org/wp-content/uploads/EducationalTechnology-in-Saudi-Arabia.pdf

9. Alshammari, N. (2014). The use of technology in education to improve student's reading skills in elementary schools. Saudi Arabia International Journal of Business and Social Science, 5(6), 69-71. Retrieved from http://www.ijbssnet.com/journals/vol_5_no_6_may_2014/6.pdf

10. Alwani, A. E. S., \&Soomro, S. (2010). Barriers to effective use of information technology in science education at Yanbu Kingdom of Saudi Arabia. In S Soomro (Ed.), E-learning experiences and future (pp. 35-46). Rijeka, Croatia: In Tech. Retrieved from https://www.researchgate.net/publication/221908579_Barriers_to_Effective_use_of_I nformation_Technology_in_Science_Education_at_Yanbu_Kingdom_of_Saudi_Arab ia

11. Asan, A. (2003). Computer technology awareness by elementary school teachers: A case study from Turkey. Journal of Information Technology Education: Research, 2, 153-164. doi: $10.28945 / 319$ 


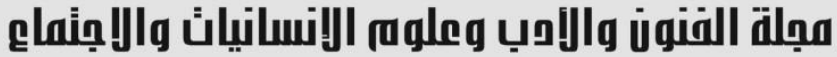 \\ Journal of Arts, Literature, Humanities and Social Sciences www.jalhss.com \\ Volume (67) May 2021 \\ العدد (67) مايو 2021}

12. Barriball, K. L., \& While, A. (1994). Collecting data using a semi-structured interview: A discussion paper. Journal of Advanced Nursing, 19, 328-335. doi:10.1111/j.1365-2648.1994.tb01088.x

13. British Educational Communications and Technology Agency (BECTA). (2004). A review of the research literature on barriers to the uptake of ICT by teachers. Retrieved from

14. http://dera.ioe.ac.uk/1603/1/becta_2004_barrierstouptake_litrev.pdf

15. Burnard, P. (1991). A method of analysing interview transcripts in qualitative research. Nurse Education Today, 11, 461-466. doi:10.1016/0260-6917(91)90009-y

16. Crotty, M. (1998). The foundations of social research: Meaning and perspective in the

17. research process. London, England: Sage.

18. Edwyn, J. (2001). Learning to change: ICT in schools. Schooling for tomorrow: Education and skills. Paris, France: OECE.

19. Ertmer, P. A., Ottenbreit-Leftwich, A. T., Sadik, O., Sendurur, E., \& Sendurur, P. (2012). Teacher beliefs and technology integration practices: A critical relationship. Computers \& Education, 59, 423-435. Retrieved from10.1016/j.compedu.2012.02.001

20. Etikan, I., Alkassim, R., \&Abubakar, S. (2016). Comparision of snowball sampling and sequential sampling technique. Biometrics \& Biostatistics International Journal, 3(1), 1-2.

21. Golafshani, N. (2003). Understanding reliability and validity in qualitative research. The

22. Qualitative Report, 8, 597-606. Retrieved from https://nsuworks.nova.edu/tqr/vol8/iss4/6/

23. Hampton, K., \& Wellman, B. (2003). Neighboring in Netville: How the Internet supports community and social capital in a wired suburb. City \& Community, 2(4), 277-311. doi:10.1046/j.1535-6841.2003.00057.x

24. Howley, A., Wood, L., \& Hough, B. (2011). Rural elementary school teachers' technology integration. Journal of Research in Rural Education, 26(9), 113.Retrieved from http://jrre.vmhost.psu.edu/wp-content/uploads/2014/02/26-9.pdf 25. Jamsheed, M. (2015). A look back at the discovery that changed the Kingdom. Saudi Aramco. Dimension International,Summer, 2-5.

26. Retrieved

from https://imgsrv2.aramcoexpats.com/pipeline/magazines/pdf_dimensions-internationalsummer-2015-part2-p4-7.pdf

27. Kalonde, G. (2017). Technology use in rural schools: A study of a rural high school trying to use iPads in the classroom. Rural Educator, 38(3), 27-38. Retrieved from http://epubs.library.msstate.edu/index.php/ruraleducator/article/view/330/401

28. Khan, M. S. H., Hasan, M., \& Clement, C. K. (2012). Barriers to the introduction of ICT into education in developing countries: The example of Bangladesh. International Journal of Instruction, 5(2), 61-80. Retrieved from https://files.eric.ed.gov/fulltext/ED533790.pdf 


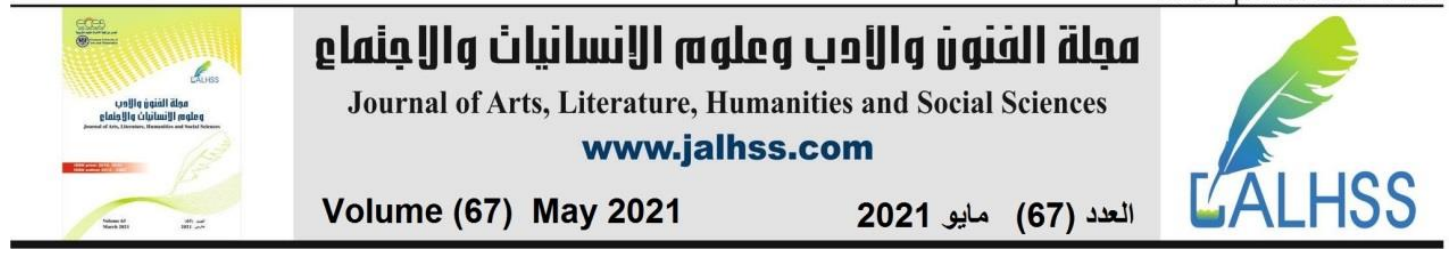

29. King, K. P. (2002). Educational technology professional development as transformative learning opportunities. Computers \& Education, 39(3), 283-297. doi:10.1016/S0360-1315(02)00073-8

30. Maslow, A. H. (1943). A theory of human motivation. Psychological review, 50(4), 370.

31. Mathers, N., Fox, N., \&Hunn, A. (2007). Surveys and questionnaires. Nottingham and Sheffield, England: The NIHR RDS for the East Midlands/Yorkshire $\&$ the Humber. Retrieved from https://www.rds-yh.nihr.ac.uk/wpcontent/uploads/2013/05/12_Surveys_and_Questionnaires_Revision_2009.pdf

32. Ministry of Education, Saudi Arabia. (n.d.). Education and Vision 2030. Retrieved from https://www.moe.gov.sa/en/Pages/Vision2030.aspx

33. Ministry of Education, Saudi Arabia. (2019). Home. Retrieved from https://www.moe.gov.sa/en/Pages/default.aspx

34. Ministry of Higher Education, Kingdom of Saudi Arabia. (2006). Saudi Arabian cultural mission to the U.S.A. Washington, DC: Saudi Arabian Cultural Mission to the U.S.A.

35. Mishra, P., \& Koehler, M. J. (2006). Technological pedagogical content knowledge: A framework for teacher knowledge. Teachers College Record, 108, 1017-1054. Retrieved

from http://one2oneheights.pbworks.com/f/MISHRA_PUNYA.pdf

36. National Center for e-Learning and Distance Learning. (2019). About us. Retrieved from http://www.elc.edu.sa/?q=en/aboutus

37. National Education Association (2019). Professional development. Retrieved from http://www.nea.org/home/30998.htm.

38. Oyaid, A. (2009). Education policy in Saudi Arabia and its relation to secondary school teachers' ICT use, perceptions, and views of the future of ICT in education (Unpublished doctoral dissertation). University of Exeter, Exeter, England. Retrieved from

https://ore.exeter.ac.uk/repository/bitstream/handle/10036/69537/OyaidA.doc.pdf?seq uence $=2$

39. Palinkas, L. A., Horwitz, S. M., Green, C. A., Wisdom, J. P., Duan, N., \&Hoagwood, K. (2015). Purposeful sampling for qualitative data collection and analysis in mixed method implementation research. Administration and Policy in Mental Health, 42(5), 533-544.

40. Pall, A. S. \&Batra, R. (2016). Adoption of ICT in instructional setup of Indian school education sector. GianJyoti Journal, 6(2), 76-87. Retrieved from https://www.gjimt.ac.in/wp-

content/uploads/2017/10/Roopali_Amanpartap_Adoption-of-ICT-in-Instructional-

Setup-of-Indian-School-Education-Sector.pdf

41. Patton, M. Q. (2002). Qualitative evaluation and research methods (3rd ed.). Thousand 


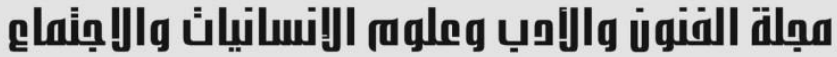 \\ Journal of Arts, Literature, Humanities and Social Sciences www.jalhss.com \\ Volume (67) May 2021 \\ العدد (67) مايو 2021

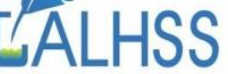

42. Oaks, CA: Sage.

43. Pelgrum, W. J. (2001). Obstacles to the integration of ICT in education: Results from a worldwide educational assessment. Computers \& Education, 37, 163-178. doi:10.1016/s0360-1315(01)00045-8

44. Poggenpoel, M., \&Myburgh, C. (2003). The researcher as research instrument in 45. educational research: A possible threat to trustworthiness? Education, 124(2), 418-421, 320. Retrieved from https://www.questia.com/library/journal/1G1$112480018 /$ the-researcher-as-research-instrument-in-educational

46. Saudi Vision 2030, Kingdom of Saudi Arabia. (2019). Home. Retrieved from https://vision2030.gov.sa/en/node

47. Sundeen, T. H., \&Sundeen, D. M. (2013). Instructional technology for rural schools: Access and acquisition. Rural Special Education Quarterly, 32(2), 8-14. doi: $10.1177 / 875687051303200203$

48. Tearle, P. (2004). A theoretical and instrumental framework for implementing change in ICT in education. Cambridge Journal of Education, 34, 331-351. doi:10.1080/0305764042000 289956

49. Tondeur, J., van Keer, H., van Braak, J., \&Valcke, M. (2008). ICT integration in the classroom: Challenging the potential of a school policy. Computers \& Education, 51, 212-223. doi:10.1016/j.compedu.2007.05.003

50. United States Department of Education. (2018). Future ready schools: Building technology infrastructure for learning. Washington, DC: Office of Educational Technology, Department of Education. Retrieved from https://tech.ed.gov/futureready/infrastructure/

51. Vareberg, K. R. (2016). It's easy until it's not: Elements contributing to rural teachers' technology use (Unpublished master's thesis). North Dakota State University, Fargo, North Dakota. Retrieved from https://library.ndsu.edu/ir/bitstream/handle/10365/27967/It\%27s\%20Easy\%20Until\% 20It $\% 27 \mathrm{~s} \% 20$ Not $\% 20$ Elements $\% 20$ Contributing $\% 20$ to $\% 20$ Rural $\% 20$ Teachers $\% 27 \%$ 20Technology $\% 20$ Use.pdf? sequence $=1 \&$ isAllowed $=\mathrm{y}$

52. Zhao, Y. \&Cziko, G. A. (2001) Teacher adoption of technology: a perceptual control

theory perspective, Journal for Technology and Teacher Education, 9(1), 5-30. 